\title{
Book Review:
}

\section{Misi Dalam Pandangan Ekumenikal dan Evangelikal Asia 1910-1961-1991}

\author{
Mission in the Ecumenical and Evangelical View of Asia 1910-1961-1991
}

\section{Author: \\ Arthur Aritonang \\ Affiliation: \\ Sekolah Tinggi Teologi \\ Cipanas \\ arthur.sttcipanas@yahoo.co.id \\ Dates: \\ Submitted: \\ 23 August 2021 \\ Accepted: \\ 20 October 2021 \\ Published: \\ 12 November 2021 \\ DOI: \\ 10.46494/psc.v17i2.153}

\section{Copyright:}

(C) 2021. The Authors. Licensee: This work is licensed under the Creative Commons Attribution-ShareAlike 4.0 International License.

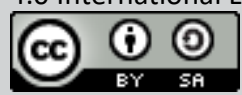

Abstract: The background of the research conducted by Richard Siwu stems from the events of the Western colonial period to countries in Asia and Africa. Previously, Siwu wanted to divide this era into two periods: the colonial era and the post-colonial era. The colonial era meant the expansion of western civilization into Africa and Asia. While the post-colonial era where the end of Western domination and the birth of new nations in Africa and Asia. In colonial times, most of the countries in Asia and Africa were colonies of European nations and were politically under the control of the West. Awareness of nationalism only grew when the influence of modernization brought by Western colonialism to Africa and Asia created a form of resistance to the West which eventually gave birth to new countries. At that time there was an assumption that Christianity was a Western religion because it came along with the expansion of the West into Asia and Africa. However, the awareness of nationalism at that time encouraged the churches in Asia in particular to break away from the domination of the Western churches and also indigenize the churches in Asia with a local style. Does the end of colonialism end the mission of the church? The answer is no because from the beginning Christianity was a missionary religion read Matthew 28:19. So, this research will analyze Protestant views in Asia regarding mission from 1910 to 1991. This research shows that after the colonial era they were polarized in two main streams: ecumenical and evangelical.

[Latar belakang dari penelitian yang dilakukan oleh Richard Siwu berpangkal pada peristiwa masa penjajahan Barat ke negara di Asia dan Afrika. Sebelumnya Siwu ingin membagi zaman tersebut menjadi dua periode: zaman kolonial dan zaman pasca kolonial. Zaman kolonial yang dimaksud berlangsungnya ekspansi peradaban barat ke Afrika dan Asia. Sedangkan zaman paska kolonial di mana berakhirnya dominasi Barat dan kelahiran bangsabangsa baru di Afrika dan Asia. Pada zaman kolonial umumnya negeri-negeri di Asia dan Afrika adalah wilayah jajahan bangsa-bangsa Eropa dan secara politis ada dalam perintah Barat. Kesadaran nasionalisme baru bertumbuh ketika pengaruh modernisasi yang dibawa oleh kolonialisme Barat ke Afrika dan Asia sehingga menciptakan bentuk perlawanan terhadap Barat yang akhirnya melahirkan negara-negara baru. Ketika itu ada anggapan bahwa kekristenan adalah agama Barat karena kedatangnya bersamaan dengan ekspansi Barat ke Asia dan Afrika. Namun kesadaran nasionalisme pada waktu itu mendorong gerejagereja secara khusus di Asia untuk melepaskan diri dominasi gereja-gereja Barat dan juga mempribumikan gereja-gereja di Asia dengan corak lokal. Apakah dengan berakhirnya zaman kolonialisme maka berakhir pula misi gereja. Jawabnnya tidak sebab sejak permulaan kekristenan adalah agama misioner baca Matius 28:19. Maka melalui penelitian ini akan menganalisi pandangan-pandangan Protestan di Asia mengenai misi pada periode 1910 sampai pada tahun 1991. Penelitian ini memperlihatkan bahwa sesudah zaman kolonial dipolarisasikan dalam dua aliran utama: ekumenikal dan evangelikal.

Keywords: ecumenical, evangelical, Western, Asian, christianity 


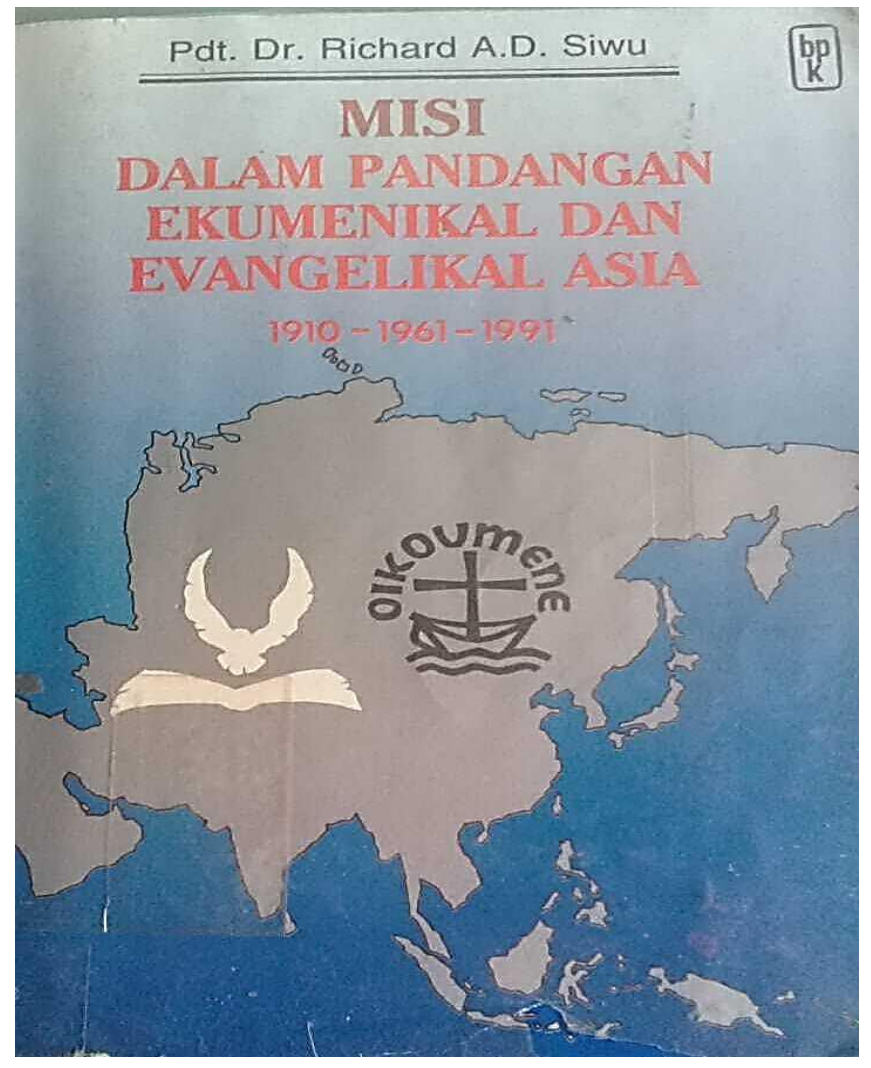

\section{Identitas Buku:}

Judul

Misi Dalam Pandangan Ekumenikal dan Evangelikal Asia 1910-1961-1991

$\begin{array}{ll}\text { Penulis } & \text { : Richard A.D. Siwu } \\ \text { Penerbit } & \text { : BPK Gunung Mulia } \\ \text { Tahun } & : \text { 1996 } \\ \text { Kota Terbit } & \text { : Jakarta } \\ \text { Cetakan } & : \text { Pertama } \\ \text { Halaman } & : \text { 453 halaman } \\ \text { ISBN } & : 979-415-864-X\end{array}$

\section{Author:}

Richard A.D. Siwu adalah pendeta Gereja Masehi Injili di Minahasa (GMIM). Setelah menyelesaikan studi S1 di STT Jakarta (1976), ia melanjutkan studinya di beberapa perguruan tinggi di Amerika Serikat: Universitas Dubuque
(1982); Christian Theological Seminary (1983); dan Lexington Theological Seminary (1985). Pada tanggal 10 Nopember 1994 penulis berhasil mempertahankan disertasinya dalam bidang misiologi pada Universitas Utrech, negeri Belanda. Kini ia bekerja sebagai dosen program Pasca Sarjana UKIT Tomohon dan UNSRAT Manado, di samping memberi kuliah Agama di IKIP Manado di Tondano. Ia juga pernah menjabat sebagai Wakil Ketua Badan Pekerja Sinode GMIM, periode 1995-2000.

\section{Summary:}

Buku yang berjudul Misi dalam Pandangan Ekumenikal dan Evangelikal Asia 1910-19611991 merupakan sebuah ringkasan dari disertasi Richard Siwu yang berhasil dipertahankan di kampus University Utrech, Belanda. Bagi pembaca buku ini masih relevan dibaca oleh kalangan akademisi kristen karena melalui buku ini pembaca akan mendapatkan deskripsi yang holistik dan komprehensif tentang misi dan metode/praksis misi di kalangan kekristenan yang dimulai sejak abad ke-20. Pada bagian pemabahasan pembaca hanya akan menyajikan garis besar saja terhadap isi dari buku.

Polarisasi ekumenikal dan Evangelikal di dalam tubuh gereja Protestan bukan terjadi baru-baru ini melainkan sudah terjadi di abad ke-2o hal tersebut berpangkal pada peristiwa paska perang dunia II dimana sebelum tahun 1961 kalangan Kristen Protestan memiliki kesepahaman yang sama mengenai orientasi misioner yang berpangkal pada badan-badan misioner Barat yang mengemban misi Kristus secara eksklusif ke seluruh dunia. Paska perang dunia II dunia ketika itu sedang memasuki masa transisi dari era imperlialisme dan kolonialisme menuju ke arah era nasionalisme. Di mana ketika itu munculnya negara-negara baru khususnya di Asia. Di masa penjajahan Barat ketika itu ekspansi peradaban Eropa 
seperti: industrialisme, modernisme, sekularisme dan corak kebudayaan Barat menyebar secara luas ke dalam kehidupan masyarakat di Asia. Di tambah lagi, perjumpaan antara kekristenan dengan agamaagama non-Kristen. Pada masa itu persepsi lama kekristenan Barat belum bergeser yang memiliki cita-cita untuk mengkristenkan dunia non-Barat (hal. 15-20).

Sehubungan dengan itu kita sekilas perlu melihat kebelakang sebelum tahun 1961 hal-hal yang melatarbelakangi polarisasi di lembaga persekutuan gereja protestan di antaranya sebagai berikut. Pada tahun 1910 di laksanakan Konferensi Misioner se-Dunia (KMD) yang di laksanakan di Edinburgh. Pada konfrensi itu diambilnya suatu keputusan penting yakni dibentuknya sebuah lembaga yang bernama Internasional Missionary Council (IMC) atau Dewan Misi Internasional (DMI). Tujuan dibentuknya DMI untuk mengkaji masalahmasalah global tentang misi. Sejak dibentuknya DMI pada tahun 1928 di Yerusalem (Israel) untuk pertama kalinya DMI melangsungkan konferensi. Pada konferensi tersebut misi tidak lagi dipahami hanya dalam rangka perluasan kekristenan dan upaya menaklukan agama-agama non-Kristen. Di sinilah awal dari sikap keterbukaan terhadap adanya kebenaran pada agama-agama lain. Pada konferensi kedua 1938 di Tambaram (India) menghasilkan pemahaman teologis di mana segala persoalan sosial, politik, dan kebudayaan merupakan objek dari kegiatan misi gereja. Pada tahun 1947 berlangusng konferensi ketiga DMI di Whitby. Salah satu hasil signifikan dari konferensi Whitby (Kanada) ialah pembentukan DGD (Dewan Gereja-gereja Dunia). Tujuan awal dari DGD untuk membangkitkan kesadaran dikalangan pemimpin gereja akan semangat keesaan dalam rangka mengembangkan suatu kerjasama misioner di antara gereja-gereja tua (gereja barat) dan muda (gereja-gereja di Asia hasil dari PI zending Barat) (hal. 15-90).
Singkat penjelasan, sampai tahun 1961 baik orang-orang ekumenikal maupun orang-oran evengelikal dapat bertemu dan bersama dalam suatu organisai misioner DMI. Namun setelah kongres Wheaton (1966) dan Sidang Raya DGD di Uppsala (1968), mulai terjadi polarisasi di tengah DGD yang disebut sebagai sebagai gerakan ekumenikal dan gerakan evangelikal. Perselisihan ini terjadi karena dua hal (1) penggabungan DMI ke dalam DGD dan (2) pergeseran konsepsi teologi. Kalangan Kristen konservatif merasa keberatan dengan kehadiran DMI masuk ke DGD. Hal ini disebabkan terjadi pergeseran wawasan teologis dari pemahaman "terpusat pada gereja" ke pemahaman yang "terpusat pada dunia". Karena tidak sesuai pada akhirnya, kalangan kristen konservatif (evangelikal) memisahkan diri dari DGD dan membentuk organisasi baru yang bernama PED (Persekutuan Evangelikal se-Dunia) dan KLED (Komite Lausanne untuk Evangelisasi se-Dunia) (hal. 90-105).

Sejak polarisai itu terjadi baik dikalangan ekumenikal dan evangelikal, masing-masing sudah memiliki organisasi baik di tingkat internasional, Asia maupun nasioal. Organisasi ini berinisiatif untuk mengadakan sebuah pertemuan akbar yang disebut dengan kongres dan memanggil perwakilan dari gereja-gereja dalam aras gerakan ekumenikal untuk memberikan ceramah atau pandanan singkat terhadap tema-tema yang berbeda berdasarkan apa yang menjadi keprihatinan bersama baik ditingkat internasional maupun nasional. Sedangkan di kalangan evangelikal juga melakukan yang sama hanya membedakan ialah kongres ini diwakili bukan atas nama gereja melainkan badan/lembaga misi di masing-masing negara asalnya

Pada umumnya konferensi-konferensi itu mereka mencoba memaknai misi dalam konteks di Asia. Para penceramah baik dikalangan ekumenikall dan evangelikal menerapkan suatu pandangan di mana Injil dikontekstualisasikan dengan kultur/budaya di Asia tanpa lagi 
mengenakan corak dunia Barat masuk ke Asia. Dengan sebuah tujuan, agar misi dapat diterima oleh kalangan orang-orang pribumi di Asia. Hal ini disebabkan dampak perang dunia II wibawa kekristenan Barat menjadi rusak sebab pelaku terjadinya perang dunia adalah orang-orang Barat yang beragama Kristen (hal. 105-344).

Baik kalangan ekumenikal dan evangelikal terdapat perbedaan dalam teologis-misi dan metode praksisnya. Di kalangan ekumenikal menekankan perluasan Injil Kerajaan Allah yang berisikan nilai-nilai kemanusian, keadilan, kemiskinan, sosial dan politik, sedangkan dikalangan evangelikal penekanannya kepada hal-hal yang bersifat spritual di antaranya: pertobatan, lahir baru, menjangkau jiwa-jiwa yang bukan Kristen. Bagi kalangan evangelikal melihat pandangan kalangan ekumenikal dianggap liberalisme dan sekuler yang hanya mengurusi hal-hal yang bersifat duniawi. Dalam praksinya, praktik misi kalangan ekumenikal melibatkan anggotaanggota gereja untuk terlibat dalam kehiduapan sosial dan politk demi kesejahteraan masyarakat. Sedangkan kaum evangelikal memperlengkapi orang-orang awam dalam rangka mengemban Amanat Agung. Kaum evangelikal menugaskan kaum awam sebagai penginjil dengan syarat bahwa mereka harus lahir baru dan kemudian diutus menjadi misionaris. Sebaliknya bagi kaum ekumenikal 'lahir baru' tidak menjadi kriteria dan itulah 'misionaris' tidak digunakan diganti dengan 'mitra kerja' bagi masyarakat (hal. 215241).

Kemudian dalam pendekatan dalam menafsirkan Alkitab berbeda. Bagi kalanan evangelikal Alkitab cocok diterapkan di segala kultur/budaya yang ada di dunia. Maka pola pendekatan evangelikal adalah tekstual dari teks (Alkitab) kepada konteks. Sedangkan bagi kalangan ekumenikal titik berangkat dalam berteologi memperhatikan konteks kemudian ke teks (Alkitab). Disisi lain bagi ekumenikal tidak lagi menggunakan istilah 'misi' berubah menjadi 'kesaksian' sedangkan evangelikal tetap menggunkan istialah misi/evangelisasi (hal. 284-293).

Dalam aspek dialog kalangan ekumenikal menjadi dialog sebagai wadah untuk menjalin sikap saling menghargai dan menghormati di antara pemeluk agama non-Kristen dan memfokuskan perhatiaannya terhadap keprihatinan bersama terkait dengan masalahmasalah sosial dan politik dan bekerjsama dengan semua pemeluk agama. Sedangkan kalangan evangelikal menggunakan aspek dialog dalam rangka evangelisasi yakni mengkomunikasikan Injil lewat verbal (hal. 360-362).

\section{Evaluation:}

Menurut pembaca buku ini berhasil menyajikan potret mengenai polarisasi misi di dalam tubuh Protestan secara berimbang dan komprehensif. Siwu tidak sedang merendahkan pemikiran teologis-misiologis mana pun baik kaum ekumenikal maupun evangelikal. Siwu ingin mengatakan kepada kaum protestan melalui buku ini agar bisa lebih menghargai keunikan pandangan misi dari kaum ekumenikal maupun evangelikal sebab kedua gerakan misioner tersebut memiliki dasar pijak teologis dalam prakitk misi tersebut. Secara histrois gerakan baik gerakan ekumenikal maupun gerakan evangelikal adalah suatu gerakan misioner yang memiliki satu latarbelakang historis yang sama, yaitu 'kebangunan kembali' semangat keagamaan Kristen di Eropa abad 19. Kebangunan kembali agama Kristen ini ditandai oleh 'kesalehan' pribadi dan semangat untuk memberitakan Injil ke dunia luar Eropa. Kemudian polarisai ini muncul sebagai sebuah tanggapan kekristenan atau gereja terhadap (1) tantangan sekularisme (pergerakan pemisahan antara agama dan pemerintah) di Barat (2) pluralisme religius (agama) di dunia secara 
khusus di Asia. Berdasarkan faktor-faktor di atas maka yang menjadi indikator dari keberhasilan misi dari kaum ekumenikal dan evangelikal memiliki penekanan yang berbeda. Penekanan kaum ekumenikal baik di Barat maupun Asia sama terletak pada seberapa jauh perluasan nilai-nilai Injil Kerajaan Allah diimplementasikan dalam kehidupan bermasyarakat (dimensi sosial dan politik) dan membangun suatu hubungan yang toleran, saling menghormati antar penganut agama salah satunya dengan melakukan dialog lintas agama. Sedangkan kaum evangelikal terletak pada seberapa banyak jiwa yang sudah dimenangkan bagi Kristus dan penambahan jumlah Jemaat. Terkait masalah sekularisme menurut pandangan kaum evangelikal Barat hanya bisa diselesaikan dengan cara menghidupi kehidupan yang kristiani sedangkan evangelikal di Asia menekankan pertobatan dan lahir baru. Kemudian pandangan evangelikal menghadapi pluralisme agama itu sebagai sesuatu yang tidak bisa dihindarkan karena itu dialog itu diperlukan sebagai cara melaukan penginjlilan bukan sinkretisme.

Akhir kata, buku ini selalu menjadi bahan rujukan primer oleh akademisi kristen dalam mengkaji/meneliti mengenai pemahaman dan praktik misi atau pekabaran Injil di Indonesia. 